\title{
Mite and ant locked together in amber
}

\section{Fossil is oldest known specimen of a mite attached to its victim.}

\section{Davide Castelvecchi}

10 September 2014

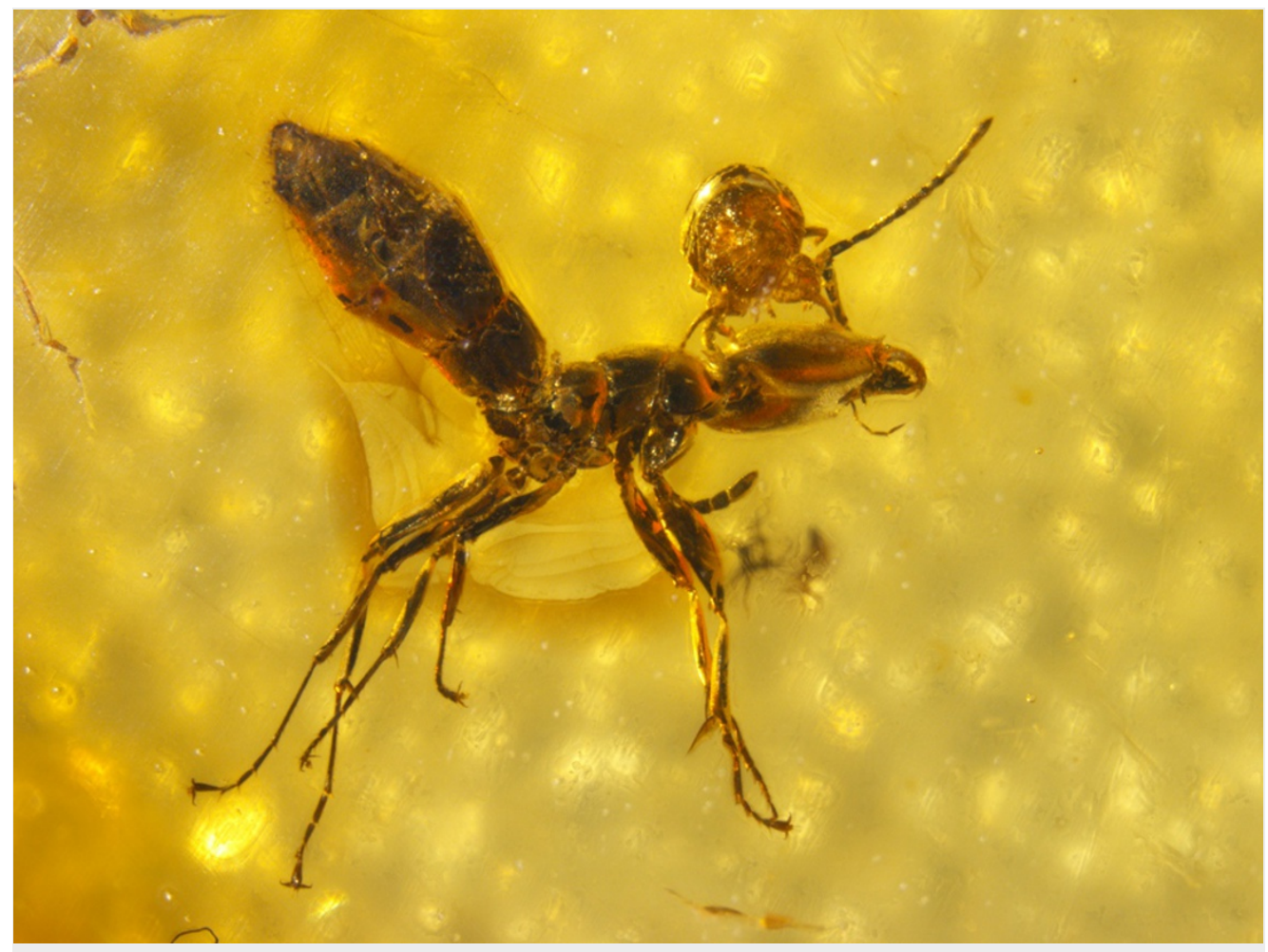

Jason Dunlop/Museumfür Naturkunde, Berlin

This ancient ant and its parasitic overlord were trapped together for eternity when they became engulfed in tree resin in the Baltic region, some time between 49 and 44 million years ago. This is only the second known example of a fossilized mite attached to its host.

The 0.7-millimetre-long mite and its victim are preserved in amber, which is fossilized tree resin. The mite appears to be firmly attached to the ant's head - a behaviour also seen in modern parasitic mites of the genus Varroa, which are often mentioned as possible culprits in the sudden collapse of honeybee colonies.

Although it is difficult to say for sure, the ancient mite was probably a parasite, too, says Jason Dunlop, an arachnologist at the Leibniz Institute for Evolution and Biodiversity Science in Berlin. "The amber mite looks very similar to modern mites, so we presume it had a similar mode of life and was parasitizing the ant rather than attacking it directly," he says.

In a paper published on 10 September in Biology Letters ${ }^{1}$, Dunlop and his collaborators identify the mite as belonging to the genus Myrmozercon, which includes numerous species still alive today. An air bubble trapped between the two invertebrates hides some anatomical features, making it hard to identify the exact species. Mites are arachnids, a class of eight-legged arthropods that includes spiders and scorpions.

"People who work on this group think that the mites suck the body fluids of the ants from time to time," says Dunlop. "The ant also carries the mite around, so that when baby mites hatch they can also crawl onto ants and be transported into the ant nest."

Dunlop received the specimen last year from Jörg Wunderlich, a German amateur arachnologist and former schoolteacher whose extensive amber collection is held in part by the Naturmuseum Senckenberg in Frankfurt. "When he buys amber, he examines it carefully for spiders, which he keeps for his own work," Dunlop says. "But if he finds something like a mite or a harvestmen [another group of arachnids], he often sends it to me." 
Nature | doi:10.1038/nature.2014.15886

\section{References}

1. Dunlop, J. A., Kontschán, J., Walter, D. E. \& Perrichot, V. Biol. Lett. 10, 20140531 (2014). 